\title{
Multiple dermatofibromas in a patient with lupus erythematosus and Sjögren's syndrome: a new case report
}

\begin{abstract}
Dermatofibroma (DF) is a common benign skin tumor. It is often a solitary lesion occurring on the lower limbs. Multiple DFs is rare. This is associated with autoimmune conditions and immunosuppression. We report a new case of multiple dermatofibromas in a patient with lupus erythematosus and Sjögren's syndrome.
\end{abstract}

Volume 3 Issue I - 2019

\author{
Samia Mrabat, Sara Elloudi, Kaoutar Laamari, \\ Hanane Baybay, Fatima Zahra Mernissi \\ University Hospital Hassan II, Morocco
}

Correspondence: Mrabat Samia, University Hospital Hassan II,
Lot N 8,Adarissa II, Fes, Morocco, Tel 002126892709 24, Email samiamrabat9I@gmail.com

Received: December 28, 2018 | Published: February 01, 2019

\section{Case report}

A 34-years- old female, was diagnosed with lupus erythematosus and Sjögren's syndrome, was treated with antimalarials and steroids. She presented few months after the diagnosis, rapid onset of cutaneous lesions. At the moment of the diagnosis, she was taking $15 \mathrm{mg}$ a day of prednisolone. Clinical examination showed 18 well-circumscribed round fierm brown round papules, with a size of 3 to $15 \mathrm{~mm}$ in diameter, with dimpling signs. The lesions were on the buttock, the thighs and the lower back. The papules were clinically typical of dermatofibromas. Dermoscopy found five different patterns: most lesions had a scar like central white patch surrounded by a pigmented network. Other patterns included a homogeneous pigmented pattern, a composed pattern, lentigo-like and seborrheic keratosis-like patterns. Excision biopsy specimen taken from the thigh found a proliferation of fibrohistiocytic spindle cells between the collagen fibers, making well-demarcated nodules located in the dermis, with no mitotic figures. The histological findings allowed us to retain the diagnosis of dermatofibroma.

\section{Discussion}

$\mathrm{DF}$ is a very common benign tumour. It often presents occurs as a single which can be observed in an otherwise healthy person. ${ }^{1}$ Multiple eruptive dermatofibromas (MEDF) are rare. ${ }^{2}$ Barf and Shapiro were the first to describe multiple eruptive dermatofibromas in $1970 .{ }^{3}$ The presence of five to eight dermatofibromas (DF) appearing within a period of 4 months or at least 15 lesions defines multiple eruptive dermatofibromas. ${ }^{4}$ Many case reports have associated the appearance of multiple dermatofibromas in patients with autoimmune diseases like systemic lupus erythematosus, myasthenia and pemphigus vulgaris. They have also been reported in patients with altered immune states as HIV infection, organ transplant, acute myeloid leukaemia. ${ }^{5}$ These findings have led to think that multiple dermatofibromas have a strong link with altered immunity state and autoimmune diseases, and so should not be considered as benign neoplasm but reactionnal tumors instead. ${ }^{4-6}$ Histologically, DFs are characterized with fibrohistiocytic proliferation made mainly of spindle-shaped cells. These spindle-shaped cells are a result of transformation of fibroblasts or endothelial cells. Recent research has led to the conclusion that DF should be considered as an immune reactive process in which dermal antigen presenting cells activate an immune response to an unknown stimulus. ${ }^{7}$ Many triggering factors have been reported such as insect bites, trauma and virus infections. ${ }^{1,8}$ Furthermore, it has been shown that the serum of patients with multiple DFs had plateletderived growth factor and fibroblast growth factor in it, these factors stimulate fibroblast proliferation and therefore lead to the appearance of DF. ${ }^{9}$ DF lesions are characterized with increased mast cells; they have a key role in the pathogenesis of DF with by secreting certain growth factors. ${ }^{10} \mathrm{MEDF}$ are clinically and histologically similar to the solitary one which is commonly present in immune competent patients (Figures 1-3). ${ }^{11}$

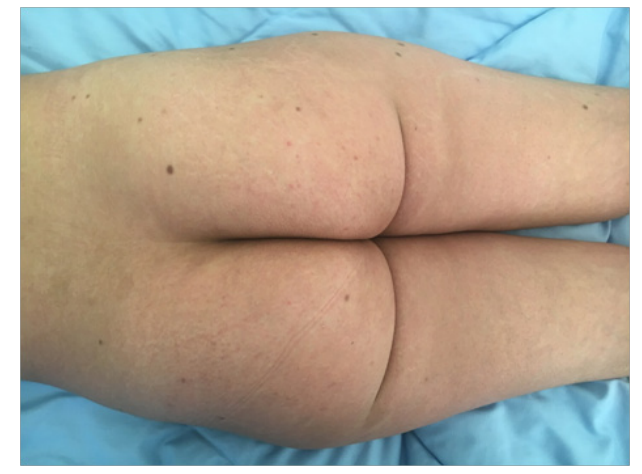

Figure I Multiples brown round papules in the buttock and the thighs

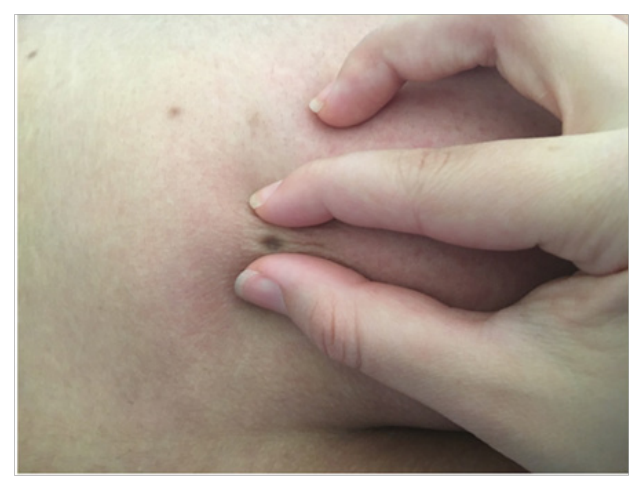

Figure 2 Positif dumpling sign in a brown papule of the buttock 


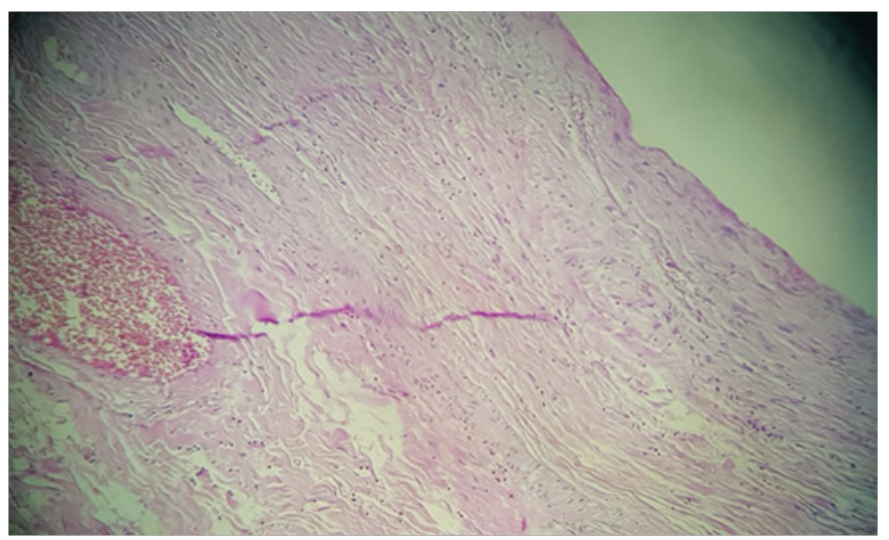

Figure 3 Histological section showing fusiform cells arranged in short bundles, with some histiocytes. Laterally, the lesion infiltrates thick dermal collagen. There are no nuclear atypies. No atypical changes in nucleus.

\section{Conclusion}

In summary, multiples dermatofibromas are often associated with altered immune states. However, there exact pathogenesis is still unknown. To our knowledge, this is the second case reporting multiples eruptive dermatofibromas in a patient with lupus erythematosus and Sjögren's syndrome.

\section{Acknowledgment}

None.

\section{Conflicts of interest}

Author declares that there is no conflict o interest.

\section{References}

1. Tsunemi Y, Tada Y, Saeki H, et al. Multiple dermatofibromas in a patient with systemic lupus erythematosus and Sjögren's syndrome. Clinical and Experimental Dermatology. 2004;29(5):483-485.

2. Niemi KM. The benign fibrohistiocytic tumors of the skin. Acta Derm Venereol Suppl (Stockh). 1970;50(63):1-66.

3. Baraf CS, Shapiro L. Multiple histiocytomas: report of a case. Arch Dermatol. 1970;101(5):588-590.

4. Niiyama S, Katsuoka K, Happle R, et al. Multiple eruptive dermatofibromas: a review of the literature. Acta Derm Venereol. 2002;82(4):241-244.

5. Massone C, Parodi A, Virno G, et al. Multiple eruptive dermatofibromas in patients with systemic lupus erythematosus treated with prednisolone. Int J Dermatol. 2002;41(5):279-281.

6. Chan I, Robson A, Mellerio JE. Multiple dermatofibromas associated with lupus profundus. Clin Exp Dermatol. 2005;30(2):128-130.

7. Zelger B, Zelger BG, Burgdorf WH. Dermatofibroma-a critical evaluation. Int J Surg Pathol. 2004;12(4):333-344.

8. Evans J, Clarke T, Mattacks CA, et al. Dermatofibromas and arthropod bites: is there any evidence to link the two? Lancet. 1989;2(8653):36-37.

9. Yamamoto T, Katayama I, Nishioka K. Involvement of basic fibroblast growth factor in fibroblast-stimulatory serum activity of a patient with systemic lupus erythematosus and multiple dermatofibromas. Dermatology. 1995;191(4):281-285.

10. Yamamoto T, Katayama I, Nishioka K. Mast cell numbers in multiple dermatofibromas. Dermatology. 1995;190(1):9-13.

11. Zaccaria E, Rebora A, Rongioletti F. Multiple eruptive dermatofibromas and immunosuppression: report of two cases and review of the literature. International Journal of Dermatology. 2008;47(7):723-727. 